\title{
Genetic variation in DNA-repair pathways and response to radiochemotherapy in esophageal adenocarcinoma: a retrospective cohort study of the Eastern Cooperative Oncology Group
}

Harry H Yoon ${ }^{1 *}$, Paul J Catalano ${ }^{2}$, Kathleen M Murphy ${ }^{3}$, Todd C Skaar ${ }^{4}$, Santosh Philips ${ }^{4}$, Mark Powell ${ }^{2}$, Elizabeth A Montgomery ${ }^{3}$, Michael J Hafez ${ }^{3}$, Steven M Offer ${ }^{1}$, Geoffrey Liư ${ }^{5}$, Stephen J Meltzer ${ }^{3}$, Xifeng Wu ${ }^{6}$, Arlene A Forastiere ${ }^{3}$, Al B Benson 7 , Lawrence R Kleinberg ${ }^{3}$ and Michael K Gibson ${ }^{8}$

\begin{abstract}
Background: Recent data in esophageal cancer suggests the variant allele of a single-nucleotide polymorphism (SNP) in XRCC1 may be associated with resistance to radiochemotherapy. However, this SNP has not been assessed in a histologically homogeneous clinical trial cohort that has been treated with a uniform approach. In addition, whether germline DNA may serve as a surrogate for tumor genotype at this locus is unknown in this disease. Our objective was to assess this SNP in relation to the pathologic complete response ( $\mathrm{CCR}$ ) rate in subjects with esophageal adenocarcinoma who received cisplatin-based preoperative radiochemotherapy in a multicenter clinical trial (Eastern Cooperative Oncology Group 1201). As a secondary aim, we investigated the rate of allelic imbalance between germline and tumor DNA.

Methods: Eighty-one eligible treatment-naïve subjects with newly diagnosed resectable esophageal adenocarcinoma received radiotherapy (45 Gy) concurrent with cisplatin-based chemotherapy, with planned subsequent surgical resection. The primary endpoint was $\mathrm{PCR}$, defined as complete absence of tumor in the surgical specimen after radiochemotherapy. Using germline DNA from 60 subjects, we examined the base-excision repair SNP, XRCC1 Arg399GIn, and 4 other SNPs in nucleotide excision (XPD Lys751GIn and Asp312Asn, ERCC1 3' flank) and double-stranded break (XRCC2 $5^{\prime}$ flank) repair pathways, and correlated genotype with pCR rate. Paired tumor tissue was used to estimate the frequency of allelic imbalance at the XRCC1 SNP.

Results: The variant allele of the XRCC1 SNP $(399 \mathrm{Gln})$ was detected in $52 \%$ of subjects. Only $6 \%$ of subjects with the variant allele experienced a pCR, compared to $28 \%$ of subjects without the variant allele (odds ratio 5.37 for failing to achieve $p C R, p=0.062$ ). Allelic imbalance at this locus was found in only $10 \%$ of informative subjects, suggesting that germline genotype may reflect tumor genotype at this locus. No significant association with $\mathrm{pCR}$ was noted for other SNPS.

Conclusions: Assessed for the first time in a prospective, interventional trial cohort of esophageal adenocarcinoma, XRCC1 399GIn was associated with resistance to radiochemotherapy. Further investigation of this genetic variation is warranted in larger cohorts. In addition, these data indicate that germline genotype may serve as a surrogate for tumor genotype at this locus.
\end{abstract}

\footnotetext{
* Correspondence: yoon.harry@mayo.edu

1 Mayo Clinic, 200 First Street SW, Rochester, MN 55905, USA

Full list of author information is available at the end of the article
} 


\section{Background}

Esophageal adenocarcinoma (EAC) is one of the fastest rising cancers in the West, particularly among white men[1]. Survival remains poor despite experimentation with numerous cytotoxic agents and therapeutic approaches, as well as improvements in diagnostic, surgical, and radiation technique[2]. In the U.S., a widely used standard to attempt to cure locally advanced disease, which is a common stage at presentation, is to provide concurrent radiochemotherapy (RCT) followed by surgery. Cisplatin often forms the base of the chemotherapy regimen[3].

This approach causes considerable toxicity in the vast majority of patients. Moreover, therapies are given with little foreknowledge of outcome. Therefore, one method to improve outcomes in EAC is to identify which patients will respond best to a particular therapeutic approach or agent - or, conversely, to identify patients who will most likely fail standard therapy so as to deliver alternative therapy at or near the outset[4]. Such patient stratification holds the potential for maximizing efficacy and minimizing toxicity.

Current methods of patient stratification in the trimodality setting - e.g., tumor grade, lymph node status, and other clinicopathologic traits - inadequately forecast clinical outcome. Therefore, the identification of biologic or molecular predictors is a rational step to tailor therapy according to an individual clinical-molecular profile.

Importantly, EAC represents a useful human model in which to study radiochemoresistance in gastrointestinal carcinomas. RCT leads to complete obliteration of tumor (i.e., complete pathologic response $[\mathrm{pCR}]$ ) in approximately $25 \%$ of EAC patients [5]. pCR has been repeatedly shown to be one of the strongest prognosticators of long-term outcome in EAC, associated with a 2- to 4-fold longer median overall survival[6-8]. Its importance is underscored by its increasing use as a primary endpoint in clinical trials for esophageal cancer. RCT typically leads to a higher pCR rate in EAC than in other gastrointestinal carcinomas, including those of the rectum[9] or pancreas[10].

Recent attention has focused on genetic variations in DNA repair pathways as a strategy for predicting response to DNA-damaging agents. DNA lesions induced by radiotherapy or cisplatin are repaired by the base excision (BER) and double-stranded break repair (DSBR) or by the nucleotide excision repair (NER) pathways, respectively. Key enzymes in these multistep complexes are XRCC1 (BER), XRCC2 (DSBR), and ERCC1 and XPD (both NER)[11]. It has been hypothesized that impaired BER/DSBR/NER activity in tumor cells leads to greater DNA damage after treatment with platins and/or ionizing radiation, thus causing greater tumor cell death[12-14]. Alternatively, greater DNA damage and genetic instability may produce tumor heterogeneity, giving rise to malignant clones that resist apoptosis after platin or radiation exposure[15].

Single nucleotide polymorphisms (SNP) in these pathways may alter DNA repair capacity. SNPs in the $X R C C 1$ gene (Arg399Gln) and XPD gene (Lys751Gln) have been associated with increased DNA damage $[16,17]$. Studies of these SNPs in EAC are only recently emerging. Efforts to identify markers that predict radioresistance, which encompasses the radiosensitizing effects of chemotherapy, would focus naturally on BER or DSBR genes. A co-investigator (X.W.) found that the XRCC1 Arg399Gln SNP (BER) was associated with pCR in esophageal cancer patients treated with cisplatinbased RCT and surgery[18]. However, this cohort was retrospectively collected over a long period (1985-2003), received heterogeneous therapeutic approaches (e.g., induction chemo prior to combined RCT were included), and combined squamous cell carcinoma (ESCC) and adenocarcinoma (EAC) histology. ESCC and EAC appear to be distinct from one another in epidemiology and biology $[1,2,19]$. Our objective in the current study was to build on this recent finding, by assessing this SNP and 4 others (ERCC1, XPD, XRCC2) in a cohort of only-EAC subjects, enrolled to a prospective, interventional clinical trial during a recent and short period and treated with cisplatin-based RCT in the first-line setting, without induction chemotherapy. We found that the relationship between the XRCC1 SNP and pCR pointed in the same direction as found by our co-investigator. To our knowledge, this is the first assessment of this SNP in EAC patients receiving RCT in a prospective clinical trial.

In addition, we assessed whether germline genotype may serve as a surrogate for tumor genotype at this $X R C C 1$ SNP by examining allelic imbalance (AI). AI is the loss or gain of a DNA region in tumor (as compared to germline) cells. This issue has relevance in both the research and clinical context. Studies evaluating the relation between SNPs and therapeutic efficacy in humans have typically studied germline DNA (peripheral blood lymphocytes or normal tissue) under the assumption that germline genotype usually reflects tumor genotype (i.e., that $\mathrm{AI}$ is rare at these loci). However, the rate of $\mathrm{AI}$ in resectable EAC at this XRCC1 SNP is unknown. A low rate of AI would provide biologic plausibility that germline genotype may be used as a surrogate for tumor genotype at these loci in predicting treatment response. Therefore, we examined tumor tissues with matched histologically normal tissues to assess AI. We found that AI at this XRCC1 SNP is uncommon; this finding supports the use of germline DNA, which is far 
more accessible clinically, when attempting to use this SNP to predict therapeutic tumor response in the tumor using this SNP to therapy.

\section{Methods}

\section{Subjects, endpoints}

DNA was obtained from subjects enrolled in ECOG trial E1201. Briefly, E1201 was a multicenter, randomized phase II trial (2002-04) that enrolled treatment-naïve subjects with newly diagnosed adenocarcinoma of esophagus or gastroesophageal junction (tumor extension $\leq 2 \mathrm{~cm}$ into gastric cardia)[20]. Other eligibility criteria included: locally advanced stage (i.e., $\mathrm{T}_{2-3} \mathrm{~N}_{0} \mathrm{M}_{0}, \mathrm{~T}_{1-3}$ $N_{1} M_{0}$ or $\left.T_{1-3} N_{0-1} M_{1 a}\right)$, surgically resectable disease $\left(T_{1-3}\right.$ but not $\mathrm{T}_{4}$ ), ECOG performance status $0-1$, and staging by endoscopic ultrasound with esophagogastroduodenoscopy and $\mathrm{CT}$ of the chest and abdomen. Subjects in both arms received radiotherapy to 45 Gy administered at 1.8 Gy per day, 5 days per week for 5 weeks, concurrently with chemotherapy. One arm received cisplatin $30 \mathrm{mg} / \mathrm{m}^{2}$ days 1 , $8,22,29$, and irinotecan $65 \mathrm{mg} / \mathrm{m}^{2}$ days $1,8,22,29$. The other arm received cisplatin $30 \mathrm{mg} / \mathrm{m}^{2}$ days $1,8,15,22$, 29, and paclitaxel $50 \mathrm{mg} / \mathrm{m}^{2}$ (1 hr) days $1,8,15,22,29$. Subjects in both arms underwent surgical resection approximately 5 weeks after the completion of RCT. The primary endpoint of E1201 as well as the current study was $\mathrm{pCR}$ - i.e., the complete absence of tumor in the resected specimen subsequent to RCT; pCR was assessed by local geographic sites during E1201, not by central review. Secondary endpoints were progression-free survival (PFS) and overall survival (OS).

\section{Retrieval and processing of specimens}

Stored paraffin-embedded tissue specimens were obtained from the ECOG Pathology Coordinating Office. Both pretreatment biopsies and posttreatment resection samples were obtained for each subject whenever available. Fresh hematoxylin and eosin-stained sections (H\&Es) were generated, then marked by an esophageal anatomic pathologist (E.A.M.) for areas containing only histologically non-malignant tissue or areas enriched $(>60 \%)$ in tumor cells. Areas of Barrett's metaplasia and dysplasia were avoided. These H\&Es were used as references for macrodissection of unstained slides. DNA was extracted from macrodissected specimens using the Qiagen QIAamp DNA FFPE Tissue Kit (Valencia, CA) following manufacturer's instructions

\section{Genotyping}

The Arg399Gln SNP within the X-ray repair complementing defective repair in Chinese hamster cells 1 (XRCC1) gene was chosen based on its prior association with complete pathologic response in esophageal cancer patients treated with RCT[18]. Other SNPs were selected if: (1) residing in a NER, BER, or DSBR pathway gene; and (2) previously associated with clinical outcome in solid-tumor patients treated with platinum-based chemotherapy[12,21-23] or with cancer risk[24]. Four additional SNPs were identified in 3 genes: excision repair cross-complementing rodent repair deficiency, complementation group 2 (XPD/ERCC2, Lys751Gln and Asp312Asn); excision repair cross-complementing rodent repair deficiency, complementation group 1 (ERCC1 3' flank, also known as "C8092A"); X-ray repair complementing defective repair in Chinese hamster cells 2 (XRCC2 5' flank, also known as “-7985T > C"). PCR and extension primers were designed on the Sequenom Assay Designer 3.1 Software (San Diego, CA) based on sequences available through the National Center for Biotechnology Information (dbSNP; http://www.ncbi. nlm.nih.gov/projects/SNP)). Allelotyping was performed using mass spectrometry-based allelotyping software and matrix-assisted laser desorption ionization-time of flight spectrometry (MALDITOF; MassArray System, Sequenom, San Diego, CA) following the manufacturer's instructions[25]. All samples were run in triplicate. The analysis of the spectra was done using the Sequenom Allelotyping Software Typer Version 4.0 (San Diego, CA; http://www.sequenom.com). MALDITOF was used to determine allelic imbalance at the XRCC1 Arg399Gln loci by dividing the allele frequency ratio of the tumor sample by the allele frequency ratio of the corresponding normal sample[26,27]. A sample was scored as showing allelic imbalance if this quotient was $\leq 0.6$ or $\geq 1.67$ (indicating that one of the alleles had decreased $40 \%$ or more) $[26,27]$.

\section{Analytic and statistical approach}

Data was pooled across both arms of the parent study and analyzed at ECOG. Lab investigators remained blinded to individual subject data throughout the study, including during data analysis. Genotypes were dichotomized a priori into 2 groups: (1) major homozygote or (2) variant allele group (heterozygote or variant-allele homozygote)[18]. Univariate comparisons were made between each SNP and clinical endpoint. Multivariate adjustments were not performed because covariates (e.g., age, performance status) were not associated with any endpoint in univariate analyses. Exact logistic regression was used to estimate odds ratios (OR) and 95\% confidence intervals (CI). All p-values and CIs are two-sided. Analyses were done in SAS version 8.2 (Cary, NC) for UNIX (SunOS). Using $\mathrm{R}^{2}$ correlation (Haploview software 4.2 , broadinstitute.org), linkage was assessed among the four SNPs on 19q (XPD, ERCC1, XRCC1). $\mathrm{R}^{2} \geq 0.80$ were considered significant. Hardy Weinberg equilibrium analysis for each SNP was calculated using R statistical software (http://www.r-project.org). 
The study was approved by the ECOG Laboratory Science Committee, ECOG Gastrointestinal Committee, and the Institutional Review Boards of Johns Hopkins and Mayo Clinic. All subjects provided informed consent.

\section{Results}

\section{Assembly and description of cohort}

Of 81 eligible subjects in E1201, 60 (74\%) consented to correlative lab studies and had sufficient DNA. These 60 subjects form the primary study population of the current analysis (Figure 1). Baseline clinicopathologic traits were: median age 57 years (38-76); male $88 \%$; white $93 \%$, black $2 \%$, Hispanic $2 \%$, Asian $3 \%$; node-negative $\left(\mathrm{T}_{2-3} \mathrm{~N}_{0} \mathrm{M}_{0}\right)$ $28 \%$, node-positive $\left(\mathrm{T}_{1-3} \mathrm{~N}_{1} \mathrm{M}_{0}\right.$ or $\left.\mathrm{T}_{1-3} \mathrm{~N}_{0-1} \mathrm{M}_{1 \mathrm{a}}\right) 72 \%$; ECOG performance status 0 (65\%) and 1 (35\%); mid- (2\%) and lower thoracic (45\%) esophagus, gastroesophageal junction (48\%), esophagus not otherwise specified (3\%), and unknown (2\%). Ten subjects achieved a pCR. The clinicopathologic features of the current study population are similar to those of the parent E1201 cohort (data not shown). Median PFS and OS were 46.5 and 46.7 months, respectively.

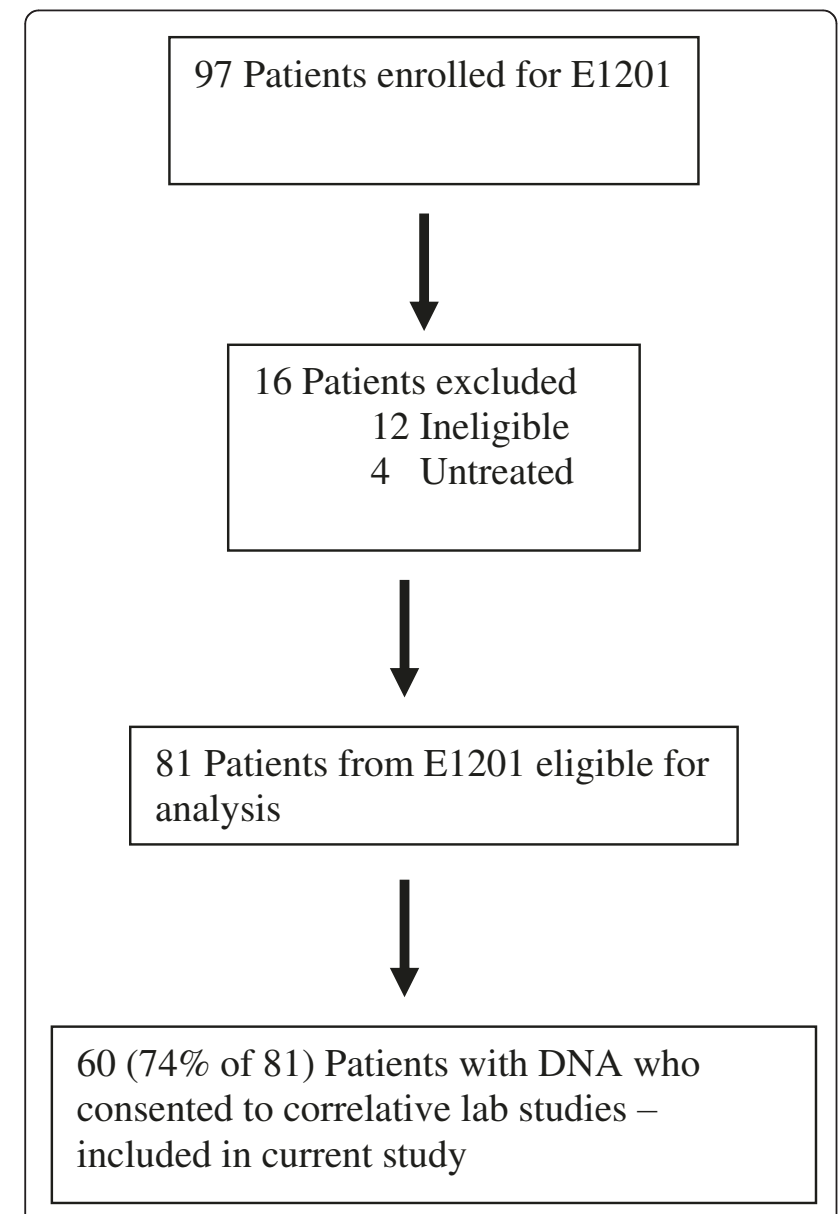

Figure 1 Patient eligibility in E1201 and sample availability.

\section{Germline genotype and outcome}

All subjects were successfully genotyped for all evaluated SNPs. The variant allele of the XRCC1 SNP (399Gln) was detected in $52 \%$ of subjects. As shown in Table 1, only $6 \%$ of subjects with the variant allele experienced a pCR, compared to $28 \%$ of subjects without the variant allele (OR 5.37 for failing to achieve pCR [95\% CI 0.94, 57.0], $\mathrm{p}=0.062)$. No significant association with $\mathrm{pCR}$ was noted for other SNPs, and no SNP was associated with PFS or OS (Table 2). Paired tumor tissue was available in 21 of 22 informative (germline heterozygote) subjects. AI was present in $2(10 \%)$ of 21 informative subjects. No significant linkage was noted for the SNPs genotyped on 19q.

Hardy-Weinberg analysis was performed in 68 subjects total, consisting of the 60 patients from the current study cohort and 8 additional subjects who enrolled in E1201 but were later deemed ineligible for the parent study. All SNPs were in Hardy-Weinberg equilibrium ( $\mathrm{p}>0.15$ ) except XRCC1 Arg399Gln ( $\mathrm{p}=0.028)$. For $X R C C 1$, the expected $v s$ observed genotype frequencies (i.e., number of subjects) were 28.5 vs 33 for GG, $31.1 v s$ 22 for AG, and 8.5 vs 13 for AA.

\section{Discussion}

The ability to predict, in the pre-RCT setting, which human EACs are radiochemosensitive has enormous clinical relevance. This is because RCT carries substantial toxicity, and because preoperative chemotherapy alone, without radiotherapy, is a valid curative alternative to RCT[28,29]. The likelihood that a patient's tumor is radiochemosensitive may be incorporated into a risk/ benefit model at the time of diagnosis which could be used as a clinical decision-making tool to select patients for preoperative RCT $v s$ chemotherapy alone. PCR is a clinically relevant marker of radiochemosensitivity, due to its consistent and strong association with overall survival in this disease[4]. Because traditional clinicalpathologic factors in the pretreatment setting do not adequately predict radiochemosensitivity, it is reasonable to evaluate molecular or genetic factors $[4,19]$.

In this study we found that $52 \%$ of EAC subjects had the variant $399 \mathrm{Gln}$ allele in $X R C C 1$, and that subjects with the variant allele had five times higher odds of failing to achieve pCR after cisplatin-based RCT, compared to subjects without the variant allele. To our knowledge, our study is the first to assess this SNP in relation to radiochemoresistance in a clinical trial cohort of EAC. This association did not reach statistical significance at the 0.05 alpha level, which may reflect our relatively modest sample size. A number of observations support the probability that our observed findings are real, and would have reached greater statistical significance had more samples been available for analysis. One, the only 
Table 1 Genotype and therapeutic response

\begin{tabular}{|c|c|c|c|c|c|c|c|}
\hline \multirow[b]{2}{*}{ SNP } & \multicolumn{2}{|c|}{ Baseline Frequency } & \multicolumn{5}{|c|}{ Association between SNPs and pCR } \\
\hline & Geno-type & No. (\%) & Variant allele group $^{\mathrm{a}}$ vs major homozygote & No pCR/pCR (No.) & OR & $95 \% \mathrm{Cl}$ & $p$ \\
\hline \multirow[t]{3}{*}{ XRCC1 Arg399GIn (rs25487) } & AA & $12(20)$ & & & & & \\
\hline & $A G$ & $19(32)$ & $A A$ or $A G$ & $29 / 2$ & & & \\
\hline & GG & $29(48)$ & GG & $21 / 8$ & 5.37 & $0.94-57.0$ & 0.062 \\
\hline \multirow[t]{3}{*}{ XRCC2 5' flank (rs6464268) } & GG & $1(2)$ & & & & & \\
\hline & GA & $16(27)$ & GG or GA & $13 / 4$ & & & \\
\hline & $\mathrm{AA}$ & $43(72)$ & AA & $37 / 6$ & 0.53 & $0.11-2.99$ & 0.59 \\
\hline \multirow[t]{3}{*}{ ERCC1 3' flank (rs3212986) } & $\pi$ & 0 & & & & & \\
\hline & GT & $22(37)$ & GT & $17 / 5$ & & & \\
\hline & GG & $38(63)$ & GG & $33 / 5$ & 0.52 & $0.10-2.60$ & 0.54 \\
\hline \multirow[t]{3}{*}{ XPD Lys751GIn (rs13181) } & GG & $8(13)$ & & & & & \\
\hline & GT & $29(48)$ & GG or GT & $30 / 7$ & & & \\
\hline & $\pi$ & $23(38)$ & $\Pi$ & $20 / 3$ & 0.64 & $0.10-3.3$ & 0.83 \\
\hline \multirow[t]{3}{*}{ XPD Asp312Asn (rs1799793) } & $\mathrm{AA}$ & $7(12)$ & & & & & \\
\hline & $A G$ & $28(47)$ & $A A$ or $A G$ & $28 / 7$ & & & \\
\hline & GG & $25(42)$ & GG & $22 / 3$ & 0.55 & $0.082-2.77$ & 0.65 \\
\hline
\end{tabular}

$\mathrm{Cl}$, confidence interval; OR, odds ratio for non-pCR of variant allele group as compared to the major homozygote; pCR, complete pathologic response; SNP, single nucleotide polymorphism.

${ }^{a}$ The variant allele group consists of the variant allele homozygote and heterozygote in combination.

other study we are aware of which assessed the relationship between this SNP in a cohort of mostly EAC patients receiving platin-based RCT and pCR (co-investigator X.W.) found the same association. Our cohort was completely independent from the first and was analyzed using a different genotyping platform.

Table 2 Genotype and survival

\begin{tabular}{|c|c|c|c|c|c|c|}
\hline \multirow[b]{2}{*}{$\begin{array}{l}\text { SNP and } \\
\text { Genotype }\end{array}$} & \multicolumn{3}{|c|}{$\begin{array}{c}\text { Progression-free } \\
\text { survival }\end{array}$} & \multicolumn{3}{|c|}{ Overall Survival } \\
\hline & $\begin{array}{l}\text { Median } \\
\text { (months) }\end{array}$ & $\mathrm{HR}$ & $p$ & $\begin{array}{l}\text { Median } \\
\text { (months) }\end{array}$ & HR & $p$ \\
\hline \multicolumn{7}{|l|}{ XRCC1:rs25487 } \\
\hline$A A$ or $A G$ & 31.5 & 1.4 & 0.41 & 23.7 & 0.86 & 0.66 \\
\hline GG & NR (>38) & & & 49.3 & & \\
\hline \multicolumn{7}{|l|}{$\begin{array}{l}\text { XRCC2: } \\
\text { rs6464628 }\end{array}$} \\
\hline GG or GA & 22.9 & 1.6 & 0.24 & 53.5 & 1.3 & 0.52 \\
\hline $\mathrm{AA}$ & NR $(>31.5)$ & & & 46.7 & & \\
\hline \multicolumn{7}{|l|}{$\begin{array}{l}\text { ERCC1: } \\
\text { rs3212986 }\end{array}$} \\
\hline GT or $\pi$ & 37.9 & 1.1 & 0.78 & 46.7 & 0.96 & 0.90 \\
\hline GG & NR $(>31.5)$ & & & 35.0 & & \\
\hline \multicolumn{7}{|l|}{ XPD:rs13181 } \\
\hline GG or GT & 46.5 & 0.63 & 0.25 & 46.7 & 0.67 & 0.27 \\
\hline$\pi$ & 16.0 & & & 21.0 & & \\
\hline \multicolumn{7}{|l|}{ XPD:rs1799793 } \\
\hline$A A$ or $A G$ & $N R(>40)$ & 0.80 & 0.57 & NR $(>40)$ & 0.59 & 0.14 \\
\hline GG & 31.4 & & & 21.0 & & \\
\hline
\end{tabular}

$\mathrm{HR}$, hazard ratio; NR, not reached; SNP, single nucleotide polymorphism.
Two, our study employed strong methodology. Therapeutic approach, staging, and disease characteristics were highly uniform, well-characterized, and prospectively collected. Our subjects were accrued over a recent, short time period across multiple centers, and staged by modern methods. Only adenocarcinoma histology was included. We focused on adenocarcinoma because of its greater relevance in the U.S., and the epidemiologic and potential biologic differences compared to squamous cell carcinoma[19]. Lab investigators remained blinded to clinical outcomes.

Three, we found that tumor genotype reflected germline genotype at the XRCC1 399 loci (19q13.2) in 90\% of informative cases, suggesting germline DNA may be an appropriate surrogate of tumor genotype. To our knowledge, this is the first reported assessment of AI specifically in XRCC1 in EAC. Comparative genomic hybridization $(\mathrm{CGH})$ studies of EAC have not found substantial genetic alterations in this general region [30,31]. One study found $>10 \%$ of 28 GEJ cancers (including 3 cell lines and 2 xenografts) had gene amplification at a neighboring site (19q13.1) [31]; however, the density of CGH coverage is not clearly reported [32] so it is unknown whether amplification occurred at XRCC1. Together, these AI data, which require further evaluation and confirmation, provides biologic plausibility that assessing germline DNA is appropriate when attempting to predict response to RCT in EAC tumors.

In addition, $X R C C 1$ is a key player in BER, the major repair pathway for nonbulky damaged bases, abasic sites, and DNA single-stranded breaks after treatment with 
ionizing radiation[33,34]. Prior reports in human populations suggested the $399 \mathrm{Gln}$ variant of XRCC1 was associated with greater DNA and chromosomal damage $[16,35]$. Worsened PCR and survival[18] related to the variant may be due to increased genetic instability and the development of multiple clonal populations, given the substantial data linking chromosomal aberrations and poor prognosis $[15,18]$. One co-investigator (G.L.) assessed this XRCC1 SNP in patients with esophageal cancer treated with cisplatin-based trimodality therapy and, similar to the current study, did not find an association with disease-free or overall survival[36]. Also consistent with our findings, the 399Gln variant allele was associated with decreased tumor response (and worse survival) in patients with stage III-IV non-small cell lung cancer (NSCLC) and metastatic colorectal cancer, respectively, treated with platinum chemotherapy $[22,37]$. By contrast, the variant allele was associated with favorable OS in patients with stage IV squamous cell carcinoma of the head and neck (SCCHN) treated with cisplatin-based chemotherapy or RCT[12]. Investigators of the latter study hypothesized their divergent result may have been due to biologic or tissue-specific factors underlying the greater chemosensitivity of SCCHN, compared to lung cancer, or to the differing types of platin compounds used in other studies (mostly carboplatin in NSCLC and oxaliplatin in colorectal cancer).

The XRCC1 SNP deviated somewhat from HardyWeinberg equilibrium, with under-representation of the heterozygote genotype $v s$ over-representation of one of the homozygous genotypes. This raises the possibility that one of the homozygous genotypes increases EAC risk, as supported by some [38] but not other [39,40] case-control data; however, our study design does not enable firm conclusions to be drawn.

Because this study focused on previously reported alleles in a few genes, we have not accounted for the potential influence of other SNPs on clinical outcome. In addition, because the two arms of the study were pooled, the study does not account for the potential differential effects of the second chemoagent of each arm. While the effect size noted in our study between the XRCC1 SNP and pCR was considerable, the results did not reach statistical significance at the alpha 0.05 level; therefore, our results should be viewed with caution pending validation in an independent cohort. Despite substantial effort to identify prognostic or predictive biomarkers in EAC, the process remains in its early stages. Because chemo- or radiotherapy deliver their effects through multigenic steps, it is unlikely that a single SNP or marker will robustly predict therapeutic efficacy. In the practical clinical context, a combination of markers will likely be required. Our finding supports the further evaluation of this XRCC1 SNP in larger cohorts.

\section{Conclusion}

EAC subjects with the variant 399Gln allele in XRCC1 had higher odds of radiochemoresistance compared to subjects without the variant allele $(p=0.062)$. To our knowledge, our study is the first to assess this SNP in relation to radiochemoresistance in a clinical trial cohort of EAC. These data support further investigation of this SNP in larger EAC populations. In addition, our data indicate that germline genotype may serve as a surrogate for tumor genotype at this locus.

\section{Author Information for Some Authors}

- HHY, lead investigator of current study, Assistant Professor of Oncology, Mayo Clinic

- MKG, lead co-investigator of current study, Assistant Professor of Medicine, Univ. of Pittsburgh

- LRK, principal investigator of E1201 parent study, Associate Professor of Radiation Oncology and Molecular Radiation Sciences, Associate Professor of Oncology, Associate Professor of Neurological Surgery, Johns Hopkins Medical Center.

- ABB, chair of ECOG-GI committee, Professor in Medicine-Hematology/Oncology, Northwestern University Medical School

- PJC and MP, ECOG biostatisticians

- XW, lead author of prior XRCC1 SNP study, Professor, Department of Epidemiology, Division of Cancer Prevention and Population Sciences, The University of Texas M. D. Anderson Cancer Center

\section{Acknowlegdements}

We thank M. Eileen Dolan, MD, for helpful discussion, and Candace Kostelec, Karen J. Hanson, and Carol Chami for administrative assistance.

\section{FUNDING:}

The parent study was conducted by the Eastern Cooperative Oncology Group (Robert L. Comis, M.D.). The parent and/or translational study were supported by an American Society of Clinical Oncology Young Investigator Award and Paul Calabresi Program in Clinical Translational Research CA90628-08U (both H.H.Y), and in part by Public Health Service Grants CA23318, CA66636, CA21115, CA13650, CA16116, CA49883, CA17145,

CA39229 from the National Cancer Institute, National Institutes of Health, and the Department of Health and Human Services. Its contents are solely the responsibility of the authors and do not necessarily represent the official views of the National Cancer Institute.

\section{PRIOR PRELIMINARY REPORTING}

These results were presented in preliminary form at ASCO Annual Meeting, May 31, 2009, and at ECOG Gastrointestinal Cancers Meeting, June 13, 2009.

\section{Author details}

${ }^{1}$ Mayo Clinic, 200 First Street SW, Rochester, MN 55905, USA. ²Dana-Farber Cancer Institute, 44 Binney Street, Boston, MA, 02115, USA. ${ }^{3}$ Johns Hopkins University, 3400 North Charles Street, Baltimore, MD, 21218, USA. ${ }^{4}$ Indiana University, 420 University Boulevard, Indianapolis, IN, 46202, USA. ${ }^{5}$ Princess Margaret Hospital, 190 Elizabeth Street, Toronto, ON, M5G 2C4, Canada. ${ }^{6} \mathrm{MD}$ Anderson Cancer Center, The University of Texas, 1515 Holcombe Boulevard, Houston, TX, 77030, USA. ${ }^{7}$ Northwestern University, 710 North Lake Shore 
Drive, Chicago, IL, 60611, USA. ${ }^{8}$ University of Pittsburgh Medical Center, 5150 Centre Avenue, 5thfloor, Pittsburgh, PA, 15232, USA.

\section{Authors' contributions}

The following authors were involved in study design: $H H Y, M K G, A B B, A A F$, KMM, GL, XW, TCK, SJM, LRK, MP, and PJC. HHY, KMM, MJH, SMO, AAF, XW, GL, SJM, EAC, SP, and TCK contributed to execution and interpretation of lab assays and/or interpretation of study results. Statistical analysis was performed by PJC and MP. All authors critically reviewed and approved the final manuscript.

\section{Competing interests}

The authors declare that they have no competing interests.

Received: 29 November 2010 Accepted: 17 May 2011

Published: 17 May 2011

\section{References}

1. Pohl H, Welch HG: The role of overdiagnosis and reclassification in the marked increase of esophageal adenocarcinoma incidence. J Natl Cancer Inst 2005, 97(2):142-146.

2. Enzinger PC, Mayer RJ: Esophageal cancer. N Engl J Med 2003, 349(23):2241-2252.

3. Herskovic A, Martz K, al-Sarraf M, Leichman L, Brindle J, Vaitkevicius V, Cooper J, Byhardt R, Davis L, Emami B: Combined chemotherapy and radiotherapy compared with radiotherapy alone in patients with cancer of the esophagus. N Engl J Med 1992, 326(24):1593-1598.

4. Yoon HH, Forastiere AA: Locally advanced esophageal adenocarcinoma: current standards and molecular predictors of outcome. Future Oncol 2008, 4(3):413-425.

5. Donahue JM, Nichols FC, Li Z, Schomas DA, Allen MS, Cassivi SD, Jatoi A, Miller RC, Wigle DA, Shen KR, Deschamp SC: Complete pathologic response after neoadjuvant chemoradiotherapy for esophageal cancer is associated with enhanced survival. Ann Thorac Surg 2009, 87(2):392-398, discussion 398-399.

6. Rohatgi PR, Swisher SG, Correa AM, Wu TT, Liao Z, Komaki R, Walsh G, Vaporciyan A, Lynch PM, Rice DC, Roth JA, Ajani JA: Failure patterns correlate with the proportion of residual carcinoma after preoperative chemoradiotherapy for carcinoma of the esophagus. Cancer 2005, 104(7):1349-1355.

7. Berger AC, Farma J, Scott WJ, Freedman G, Weiner L, Cheng JD, Wang H, Goldberg M: Complete response to neoadjuvant chemoradiotherapy in esophageal carcinoma is associated with significantly improved survival. J Clin Oncol 2005, 23(19):4330-4337.

8. Urba SG, Orringer MB, Turrisi A, lannettoni M, Forastiere A, Strawderman M: Randomized trial of preoperative chemoradiation versus surgery alone in patients with locoregional esophageal carcinoma. J Clin Oncol 2001, 19(2):305-313.

9. Ceelen WP, Van Nieuwenhove Y, Fierens K: Preoperative chemoradiation versus radiation alone for stage II and III resectable rectal cancer. Cochrane Database Syst Rev 2009, , 1: CD006041.

10. Evans DB, Varadhachary GR, Crane CH, Sun CC, Lee JE, Pisters PW, Vauthey JN, Wang H, Cleary KR, Staerkel GA, Charnsangavej C, Lano EA, Ho L, Lenzi R, Abbruzzese JL, Wolff RA: Preoperative gemcitabine-based chemoradiation for patients with resectable adenocarcinoma of the pancreatic head. J Clin Oncol 2008, 26(21):3496-3502.

11. Thacker J, Zdzienicka MZ: The XRCC genes: expanding roles in DNA double-strand break repair. DNA repair 2004, 3(8-9):1081-1090.

12. Quintela-Fandino M, Hitt R, Medina PP, Gamarra S, Manso L, CortesFunes H, Sanchez-Cespedes M: DNA-repair gene polymorphisms predict favorable clinical outcome among patients with advanced squamous cell carcinoma of the head and neck treated with cisplatin-based induction chemotherapy. J Clin Oncol 2006, 24(26):4333-4339.

13. Shellard SA, Fichtinger-Schepman AM, Lazo JS, Hill BT: Evidence of differential cisplatin-DNA adduct formation, removal and tolerance of DNA damage in three human lung carcinoma cell lines. Anticancer Drugs 1993, 4(4):491-500.

14. Helleday T, LO J, van Gent DC, Engelward BP: DNA double-strand break repair: from mechanistic understanding to cancer treatment. DNA repair 2007, 6(7):923-935
15. Albertson DG, Collins C, McCormick F, Gray JW: Chromosome aberrations in solid tumors. Nature genetics 2003, 34(4):369-376.

16. Duell EJ, Wiencke JK, Cheng TJ, Varkonyi A, Zuo ZF, Ashok TD, Mark EJ, Wain JC, Christiani DC, Kelsey KT: Polymorphisms in the DNA repair genes XRCC1 and ERCC2 and biomarkers of DNA damage in human blood mononuclear cells. Carcinogenesis 2000, 21(5):965-971.

17. Lunn RM, Helzlsouer KJ, Parshad R, Umbach DM, Harris EL, Sanford KK Bell DA: XPD polymorphisms: effects on DNA repair proficiency. Carcinogenesis 2000, 21(4):551-555.

18. Wu X, Gu J, Wu TT, Swisher SG, Liao Z, Correa AM, Liu J, Etzel CJ, Amos Cl, Huang M, Chiang SS, Milas L, Hittelman WN, Ajani JA: Genetic variations in radiation and chemotherapy drug action pathways predict clinical outcomes in esophageal cancer. J Clin Oncol 2006, 24(23):3789-3798

19. Kleinberg L, Forastiere AA: Chemoradiation in the management of esophageal cancer. J Clin Oncol 2007, 25(26):4110-4117.

20. Kleinberg L, Powell ME, Forastiere A, Keller S, Anne P, Benson AB: E1201: An Eastern Cooperative Oncology Group (ECOG) randomized phase II trial of neoadjuvant preoperative paclitaxel/cisplatin/RT or irinotecan/ cisplatin/RT in endoscopy with ultrasound (EUS) staged adenocarcinoma of the esophagus. Journal of Clinical Oncology ASCO Annual Meeting Proceedings Part / 2007, 25(185):4533.

21. Park D, Stoehlmacher J, Zhang W, Tsao-Wei DD, Groshen S, Lenz HJ: A Xeroderma Pigmentosum Group D Gene Polymorphism Predicts Clinical Outcome to Platinum-based Chemotherapy in Patients with Advanced Colorectal Cancer. Cancer Res 2001, 61:8654-8658.

22. Gurubhagavatula S, Liu G, Park S, Zhou W, Su L, Wain JC, Lynch TJ, Neuberg D, Christiani DC: XPD and XRCC1 Genetic Polymorphisms Are Prognostic Factors in Advanced Non-Small-Cell Lung Cancer Patients Treated with Platinum Chemotherapy. Journal of Clinical Oncology 2004, 22(13):2594-2601.

23. Bradbury PA, Kulke MH, Heist RS, Zhou W, Ma C, Xu W, Marshall AL, Zhai R, Hooshmand SM, Asomaning K, Su L, Shepherd FA, Lynch TJ, Wain JC, Christiani DC, Liu G: Cisplatin pharmacogenetics, DNA repair polymorphisms, and esophageal cancer outcomes. Pharmacogenetics and genomics 2009, 19(8):613-625.

24. Figueroa JD, Malats N, Rothman N, Real FX, Silverman D, Kogevinas M Chanock S, Yeager M, Welch R, Dosemeci M, Tardon A, Serra C, Carrato A, Garcia-Closas R, Castano-Vinyals G, Garcia-Closas M: Evaluation of genetic variation in the double-strand break repair pathway and bladder cancer risk. Carcinogenesis 2007, 28(8):1788-1793.

25. Luan J, Yuan J, Li X, Jin S, Yu L, Liao M, Zhang H, Xu C, He Q, Wen B, Zhong $X$, Chen X, Chan HL, Sung JJ, Zhou B, Ding C: Multiplex detection of 60 hepatitis $B$ virus variants by maldi-tof mass spectrometry. Clinical chemistry 2009, 55(8):1503-1509.

26. Ollikainen M, Hannelius U, Lindgren CM, Abdel-Rahman WM, Kere J, Peltomaki P: Mechanisms of inactivation of MLH1 in hereditary nonpolyposis colorectal carcinoma: a novel approach. Oncogene 2007, 26(31):4541-4549.

27. Ollikainen M, Abdel-Rahman WM, Moisio AL, Lindroos A, Kariola R, Jarvela I, Poyhonen M, Butzow R, Peltomaki P: Molecular analysis of familial endometrial carcinoma: a manifestation of hereditary nonpolyposis colorectal cancer or a separate syndrome? I Clin Oncol 2005, 23(21):4609-4616.

28. Cunningham D, Allum WH, Stenning SP, Thompson JN, Van de Velde CJ, Nicolson M, Scarffe JH, Lofts FJ, Falk SJ, Iveson TJ, Smith DB, Langley RE, Verma M, Weeden S, Chua YJ, MAGIC Trial Participants: Perioperative chemotherapy versus surgery alone for resectable gastroesophageal cancer. N Engl J Med 2006, 355(1):11-20.

29. MRC G: Surgical resection with or without preoperative chemotherapy in oesophageal cancer: a randomised controlled trial. Lancet 2002, 359(9319):1727-1733.

30. Nancarrow DJ, Handoko HY, Smithers BM, Gotley DC, Drew PA, Watson DI, Clouston AD, Hayward NK, Whiteman DC: Genome-wide copy number analysis in esophageal adenocarcinoma using high-density singlenucleotide polymorphism arrays. Cancer Res 2008, 68(11):4163-4172.

31. van Dekken H, Geelen E, Dinjens WN, Wijnhoven BP, Tilanus HW, Tanke HJ, Rosenberg C: Comparative genomic hybridization of cancer of the gastroesophageal junction: deletion of 14Q31-32.1 discriminates between esophageal (Barrett's) and gastric cardia adenocarcinomas. Cancer Res 1999, 59(3):748-752. 
32. Kallioniemi A, Kallioniemi OP, Sudar D, Rutovitz D, Gray JW, Waldman F, Pinkel D: Comparative genomic hybridization for molecular cytogenetic analysis of solid tumors. Science (New York, NY 1992, 258(5083):818-821.

33. Kinsella TJ: Coordination of DNA mismatch repair and base excision repair processing of chemotherapy and radiation damage for targeting resistant cancers. Clin Cancer Res 2009, 15(6):1853-1859.

34. Caldecott KW: XRCC1 and DNA strand break repair. DNA repair 2003, 2(9):955-969.

35. Lunn RM, Langlois RG, Hsieh LL, Thompson CL, Bell DA: XRCC1 polymorphisms: effects on aflatoxin B1-DNA adducts and glycophorin A variant frequency. Cancer Res 1999, 59(11):2557-2561.

36. Bradbury P, Marshall A, Kulke M, Zhou W, Heist R, Su L, Lynch T, Shepherd F, Christiani D, Liu G: Prognostic significance of nuclear excision (NER) and base excision (BER) DNA repair gene polymorphisms in esophageal cancer. Journal of Clinical Oncology, ASCO Annual Meeting Proceedings Part I 2007, 25(18S):2511.

37. Stoehlmacher J, Ghaderi V, lobal S, Groshen S, Tsao-Wei D, Park D, Lenz HJ: A polymorphism of the XRCC1 gene predicts for response to platinum based treatment in advanced colorectal cancer. Anticancer Res 2001. 21(4B):3075-3079.

38. Doecke J, Zhao ZZ, Pandeya N, Sadeghi S, Stark M, Green AC, Hayward NK, Webb PM, Whiteman DC: Polymorphisms in MGMT and DNA repair genes and the risk of esophageal adenocarcinoma. Int J Cancer 2008, 123(1):174-180.

39. Tse D, Zhai R, Zhou W, Heist RS, Asomaning K, Su L, Lynch TJ, Wain JC, Christiani DC, Liu G: Polymorphisms of the NER pathway genes, ERCC1 and XPD are associated with esophageal adenocarcinoma risk. Cancer Causes Control 2008, 19(10):1077-1083.

40. Ferguson HR, Wild CP, Anderson LA, Murphy SJ, Johnston BT, Murray LJ, Watson RG, McGuigan J, Reynolds JV, Hardie LI: No association between hOGG1, XRCC1, and XPD polymorphisms and risk of reflux esophagitis, Barrett's esophagus, or esophageal adenocarcinoma: results from the factors influencing the Barrett's adenocarcinoma relationship casecontrol study. Cancer Epidemiol Biomarkers Prev 2008, 17(3):736-739.

Pre-publication history

The pre-publication history for this paper can be accessed here: http://www.biomedcentral.com/1471-2407/11/176/prepub

doi:10.1186/1471-2407-11-176

Cite this article as: Yoon et al: Genetic variation in DNA-repair pathways and response to radiochemotherapy in esophageal adenocarcinoma: a retrospective cohort study of the Eastern Cooperative Oncology Group. BMC Cancer 2011 11:176.

\section{Submit your next manuscript to BioMed Central and take full advantage of:}

- Convenient online submission

- Thorough peer review

- No space constraints or color figure charges

- Immediate publication on acceptance

- Inclusion in PubMed, CAS, Scopus and Google Scholar

- Research which is freely available for redistribution

Submit your manuscript at www.biomedcentral.com/submit
Biomed Central 